(1)

CrossMark

\title{
Neuropeptide regulation of secretion and inflammation in human airway gland serous cells
}

\author{
Derek B. McMahon ${ }^{1}$, Ryan M. Carey ${ }^{1}$, Michael A. Kohanski ${ }^{1}$, Charles C.L. Tong (1) \\ Peter Papagiannopoulos ${ }^{1}$, Nithin D. Adappa ${ }^{1}$, James N. Palmer ${ }^{1}$ and \\ Robert J. Lee (1) ${ }^{1,2}$
}

Affiliations: ${ }^{1}$ Dept of Otorhinolaryngology, University of Pennsylvania Perelman School of Medicine, Philadelphia, PA, USA. ${ }^{2}$ Dept of Physiology, University of Pennsylvania Perelman School of Medicine, Philadelphia, PA, USA.

Correspondence: Robert J. Lee, Dept of ORL-HNS, Hospital of the University of Pennsylvania, 3400 Spruce Street, 5th floor Ravdin, Suite A, Philadelphia, PA 19104, USA. E-mail: rjlapennmedicine.upenn.edu

@ERSpublications

VIP and NPY are neuropeptides up-regulated in allergy and asthma, respectively, which inversely regulate CFTR-dependent secretion and inflammation in airway submucosal gland serous cells, and which secrete much of the fluid that lines conducting airways http://bit.ly/2FWNT29

Cite this article as: McMahon DB, Carey RM, Kohanski MA, et al. Neuropeptide regulation of secretion and inflammation in human airway gland serous cells. Eur Respir J 2020; 55: 1901386 [https://doi.org/ 10.1183/13993003.01386-2019].

ABSTRACT Airway submucosal gland serous cells are sites of expression of the cystic fibrosis transmembrane conductance regulator (CFTR) and are important for fluid secretion in conducting airways. To elucidate how neuropeptides regulate serous cells, we tested if human nasal turbinate serous cells secrete bicarbonate $\left(\mathrm{HCO}_{3}^{-}\right)$, important for mucus polymerisation and antimicrobial peptide function, during stimulation with cAMP-elevating vasoactive intestinal peptide (VIP) and if this requires CFTR. Serous cells stimulated with VIP exhibited a 15-20\% cAMP-dependent decrease in cell volume and a $\sim 0.15$ unit decrease in intracellular $\mathrm{pH}\left(\mathrm{pH}_{\mathrm{i}}\right)$, reflecting activation of $\mathrm{Cl}^{-}$and $\mathrm{HCO}_{3}^{-}$secretion, respectively. $\mathrm{HCO}_{3}^{-}$secretion was directly dependent on CFTR and was absent in cells from CF patients. In contrast, neuropeptide Y (NPY) reduced VIP-evoked cAMP increases, CFTR activation, and $\mathrm{Cl}^{-} / \mathrm{HCO}_{3}^{-}$ secretion. Culture of primary serous cells in a model that maintained a serous phenotype confirmed the activating and inhibiting effects of VIP and NPY, respectively, on fluid and $\mathrm{HCO}_{3}^{-}$secretion. Moreover, VIP enhanced antimicrobial peptide secretion and antimicrobial efficacy of secretions while NPY reduced antimicrobial efficacy. In contrast, NPY enhanced cytokine release while VIP reduced cytokine release through a mechanism requiring CFTR. As levels of VIP and NPY are up-regulated in diseases like allergy, asthma, and chronic rhinosinusitis, the balance of these two peptides in the airway may control mucus rheology and inflammatory responses in serous cells. Furthermore, the loss of CFTR conductance in serous cells may contribute to $\mathrm{CF}$ pathophysiology by increasing serous cells inflammatory responses in addition to directly impairing $\mathrm{Cl}^{-}$and $\mathrm{HCO}_{3}^{-}$secretion.

This article has an editorial commentary: https://doi.org/10.1183/13993003.00466-2020

This article has supplementary material available from erj.ersjournals.com

Received: 12 July 2019 | Accepted after revision: 13 Jan 2020

Copyright OERS 2020 


\section{Introduction}

Several obstructive airway diseases share phenotypes of thickened mucus, including chronic rhinosinusitis (CRS), cystic fibrosis (CF), asthma and COPD [1-3]. From nasal turbinate down to small bronchi, a large percentage of airway-surface liquid (ASL) and mucus is generated by submucosal exocrine glands [3]. Gland serous cells are sites of expression of the CF transmembrane conductance regulator (CFTR) [3]. Observations of occluded gland ducts and gland hypertrophy, hyperplasia and infection in CF [3] suggest that defects in CFTR-dependent serous secretion contribute to CF pathology. Intact CF glands secrete less fluid in response to cAMP-elevating agonists such as vasoactive intestinal peptide (VIP) compared with non-CF glands [3]. Gland hypertrophy, duct plugging, and excess mucus are also observed in COPD and asthma [3], with gland hypertrophy more common in fatal asthma [4].

Bicarbonate $\left(\mathrm{HCO}_{3}^{-}\right)$secretion by serous cells facilitates polymerisation of mucins secreted by more proximal mucous cells [5] (supplementary figure $\mathrm{S} 1 \mathrm{a}$ ). $\mathrm{HCO}_{3}^{-}$is also critical to efficacy of antimicrobial peptides secreted by serous cells [3]. However, mechanisms by which serous cells secrete $\mathrm{HCO}_{3}^{-}$are unknown. Identifying these mechanisms may yield insights into pathophysiology of CF and other diseases exhibiting altered mucus secretion or rheology. We previously studied nasal serous cell $\mathrm{HCO}_{3}^{-}$secretion during cholinergic-induced secretion [6], which is largely intact in CF [3], as it is mediated by the $\mathrm{Ca}^{2+}$-activated $\mathrm{Cl}^{-}$and $\mathrm{HCO}_{3}^{-}$channel (CaCC) TMEM16A [7]. Our initial goal was to directly test if serous cells also secrete $\mathrm{HCO}_{3}^{-}$during VIP stimulation, if this occurs through CFTR, and if TMEM16A could substitute during loss of CFTR.

A further goal was to understand how VIP and neuropeptide Y (NPY), both upregulated in inflammatory airway diseases, interact to control airway secretion. Parasympathetic VIPergic $[8,9]$ and NPYergic $[10$, 11] neurons exist in the respiratory tract and may be increased in mucosa from patients with allergic rhinitis [12] or irritative toxic rhinitis [13]. Some nerves co-express VIP and NPY [14], including in the proximity of glands $[15,16]$. VIP and NPY are found in the pedicle of nasal polyps, suggesting they may play a role in polyp formation [17]. Activated macrophages [18] or epithelial cells [19] can also make NPY, perhaps because NPY has direct antimicrobial effects [20]. Elevated NPY in asthma [21] may link psychological stress with allergic asthma exacerbations [22]. Mice lacking NPY or NPY1R have reduced allergic airway inflammation [23]. Other studies outside the airway suggest NPY increases T helper (Th)2 responses [24, 25]. NPY and NPYR1 expression are elevated in mouse lungs after influenza, and knockout of NPY reduced disease severity and interleukin (IL)-6 levels [18]. Allergic rhinitis patients have nasal secretions with elevated concentrations of VIP compared with control individuals at baseline [26] and during allergen challenge [27].

A recent review highlighted the need for elucidation of neuropeptide regulation of submucosal glands in obstructive lung diseases [28]. The role of VIP as a cAMP-dependent activator of secretion is established [3], but the role of NPY is unclear. A cocktail of NPY and noradrenaline inhibited cultured tracheal gland cell glycoprotein secretion [29], and NPY inhibited bulk mucus secretion in ferret trachea [30], but there is little mechanistic data for if/how NPY affects serous cells. NPY receptors are often $\mathrm{G}_{\mathrm{i}}$-coupled and could reduce cAMP responses to $\mathrm{G}_{\mathrm{s}}$-coupled VIP receptors [31], reducing secretion by lowering protein kinase A (PKA) activation of CFTR. Moreover, VIP and NPY are immunomodulators [32] and may regulate gland cytokine secretion.

We examined effects of VIP and NPY in primary serous cells isolated from human nasal glands. Cells were studied acutely as well as in an air-liquid interface (ALI) culture model that retained expression of serous cell markers, facilitating polarised studies and co-culture with human macrophages. Results below contribute to our understanding of airway serous cells and the role of CFTR in both secretion and inflammation, suggesting therapeutic targets for obstructive airway diseases.

\section{Methods}

Experimental procedures

Isolation of primary serous acinar cells, immunofluorescence and live cell imaging of cell volume, $\mathrm{pH}_{\mathrm{i}}$, and $\mathrm{Cl}^{-}$was carried out as described [6,33]. Culture of gland serous cells was carried out as described [34]. ASL height, ASL pH measurements, ELISAs and bacterial assays were carried out as reported [27, 35]. More detailed methods and reagents used provided in the supplementary materials.

\section{Study approval}

Tissue was acquired in accordance with the University of Pennsylvania guidelines regarding residual clinical material in research (IRB protocol \#800614), the US Department of Health and Human Services Title 45 CFR 46.116, and the Declaration of Helsinki. Turbinate samples from 42 non-CF and nine CF patients (seven $\Delta \mathrm{F} 508 / \Delta \mathrm{F} 508$, one $\Delta \mathrm{F} 508 / \mathrm{G} 542 \mathrm{X}$, and one $\Delta \mathrm{F} 508 / \mathrm{E} 585 \mathrm{X}$ ) were used (supplementary table S1). 


\section{Statistics}

Data were analysed in GraphPad Prism. Multiple comparisons used 1-way ANOVA with Bonferroni (preselected pairwise comparisons), Dunnett's (comparisons to a control set) or Tukey-Kramer (comparison of all values) post-tests. A p-value $<0.05$ was considered significant. All data are mean \pm SEM from independent experiments using cells from $\geqslant 4$ patients. Minimal patient-to-patient variability was observed beyond effects of CFTR genetype, as described in the supplementary material. Data points in each figure represent independent experiments, some of which used separate cell cultures that originated from the same patient (common in studies using ALI cultures). In this case, an equal number of independent experiments, typically two, was performed using cells from each patient to ensure that cells from each patient were equally represented to prevent cells from any one patient skewing results.

\section{Results}

VIP stimulates $\mathrm{Cl}^{-}$and $\mathrm{HCO}_{3}^{-}$secretion through CFTR

Submucosal gland acinar cells (supplementary figure S1b) were isolated from human middle turbinate [33]. Serous acini exhibited secretory-granule immunofluorescence for lysozyme (supplementary figure S1c), basolateral immunofluorescence for VIP receptors (supplementary figure S1d and e), and apical immunofluorescence for TMEM16A and CFTR (supplementary figure S1f and g) as described [6, 7, 33]. Secretion was studied in isolated serous cells using simultaneous differential interference contrast (DIC) measurement of cell volume and quantitative fluorescence microscopy of indicator dyes to measure the concentrations of ions involved in driving secretion $\left(\mathrm{Cl}^{-} / \mathrm{HCO}_{3}^{-}\right)$, a technique pioneered in salivary cells adapted for serous cells $[6,7,33]$.

Epithelial fluid secretion is driven largely by $\mathrm{Cl}^{-}$. Serous cell shrinkage during agonist stimulation reflects efflux of cellular $\mathrm{K}^{+}$and $\mathrm{Cl}^{-}$upon activation of secretion and movement of osmotically obliged water. Cell swelling upon removal of agonist reflects solute uptake via mechanisms that sustain secretion, such as the $\mathrm{Na}^{+} \mathrm{K}^{+} 2 \mathrm{Cl}^{-}$co-transporter NKCC1 [7] (figure 1a). Human nasal serous cells shrank by $\sim 20 \%$ when stimulated with cAMP-elevating agonists forskolin or VIP (figure 1b), as previously reported [33].

Shrinkage was accompanied by transient acidification of intracellular $\mathrm{pH}\left(\mathrm{pH}_{\mathrm{i}}\right)$ followed by more sustained alkalinisation (figure $1 \mathrm{c}$ and $\mathrm{d}$ ). Agonist-evoked acidification was absent in $\mathrm{HCO}_{3}^{-}$-free media (supplementary figure S2a-c), and the secondary alkalinisation was blocked with inhibition of the $\mathrm{Na}^{+} \mathrm{HCO}_{3}^{-}$co-transporter (NBC; supplementary figure $\mathrm{S} 2 \mathrm{~d}$ ). Thus, the transient acidification reflects $\mathrm{HCO}_{3}^{-}$efflux during activation of secretion, while the alkalinisation reflects activation of $\mathrm{NBC}$, sustaining $\mathrm{HCO}_{3}^{-}$secretion by keeping intracellular $\left[\mathrm{HCO}_{3}^{-}\right]$high. This is similar to cholinergic-evoked serous cell acidification and subsequent alkalinisation by $\mathrm{Na}^{+} / \mathrm{H}^{+}$exchangers (NHEs) [6], but reveals an important mechanistic difference between cAMP and $\mathrm{Ca}^{2+}$ pathways.

Acidification was blocked by eliminating the driving forces for conductive $\mathrm{HCO}_{3}^{-}$efflux using ion substitution (supplementary figure S2e), suggesting acidification is mediated by an ion channel. Forskolinor VIP-induced shrinkage and acidification were absent in cells from CF patients (figure $1 \mathrm{c}$ and $\mathrm{d}$ ), and were inhibited by CFTR inhibitor $\mathrm{CFTR}_{\mathrm{inh}} 172$ or $\mathrm{K}^{+}$channel inhibitors clofilium and clotrimazole in non-CF cells (figure 1e and f), demonstrating a requirement for both CFTR and counterion $\mathrm{K}^{+}$efflux. VIP-evoked responses were not reduced by TMEM16A inhibitors niflumic acid (NFA), T16 $\mathrm{A}_{\text {inh }}$-A01, $\mathrm{CaCC}_{\text {inh- }}$-A01, or 4,4'-diisothiocyanato-2,2'-silbenedisulfonic acid (DIDS) (figure 1f). Representative traces are in supplementary figure $\mathrm{S} 3 \mathrm{a}$ and $\mathrm{b}$.

In contrast, carbachol $(\mathrm{CCh})$, which activates $\mathrm{Ca}^{2+}$-driven secretion $[7,33]$, stimulated shrinkage and acidification blocked by TMEM16A inhibitors NFA, T16 $\mathrm{A}_{\text {inh }}-\mathrm{A} 01, \mathrm{CaCC}_{\text {inh }}-\mathrm{A} 01$, or DIDS (figure $1 \mathrm{~g}$ ). CCh-induced secretion was intact in CF cells (figure 1h). Pharmacological activation of TMEM16A ( $\mathrm{E}_{\text {act }}$ ) restored secretion responses to VIP in CF cells (figure $1 \mathrm{~h}$ ). Representative traces are in supplementary figure $\mathrm{S} 3 \mathrm{c}$ and $\mathrm{d}$. The concentration of $\mathrm{E}_{\mathrm{act}}$ used here had no acute (2-3 min) effects on intracellular calcium in these cells (supplementary figure S3e)

Thus, cAMP elevation activates both $\mathrm{Cl}^{-}$and $\mathrm{HCO}_{3}^{-}$secretion directly through CFTR (figure 1i), and targeting TMEM16A might restore $\mathrm{HCO}_{3}^{-}$secretion in CF glands. We found no evidence for $\mathrm{Cl}^{-} / \mathrm{HCO}_{3}^{-}$ exchanger-mediated $\mathrm{HCO}_{3}^{-}$efflux (supplementary figure S4), agreeing with data showing Calu-3 cells [36], a bronchial line frequently used as a serous cell surrogate, secrete $\mathrm{HCO}_{3}^{-}$mainly through $\mathrm{CFTR}$ while $\mathrm{Cl}^{-} /$ $\mathrm{HCO}_{3}^{-}$exchanger pendrin (SLC26A4) is more important in surface epithelial cells. These data show a fundamental defect in $\mathrm{HCO}_{3}^{-}$secretion in $\mathrm{CF}$ cells caused directly by loss of CFTR conductance, which may be restored directly by pharmacological CFTR correction.

NPY reduces CFTR-mediated fluid and $\mathrm{HCO}_{3}^{-}$secretion during VIP stimulation

Calu-3s express high amounts of NPY1R relative to other airway lines (supplementary tables S2 and S3). We thus tested for NPYRs in primary serous cells. We observed no secretory responses to NPY, but the 

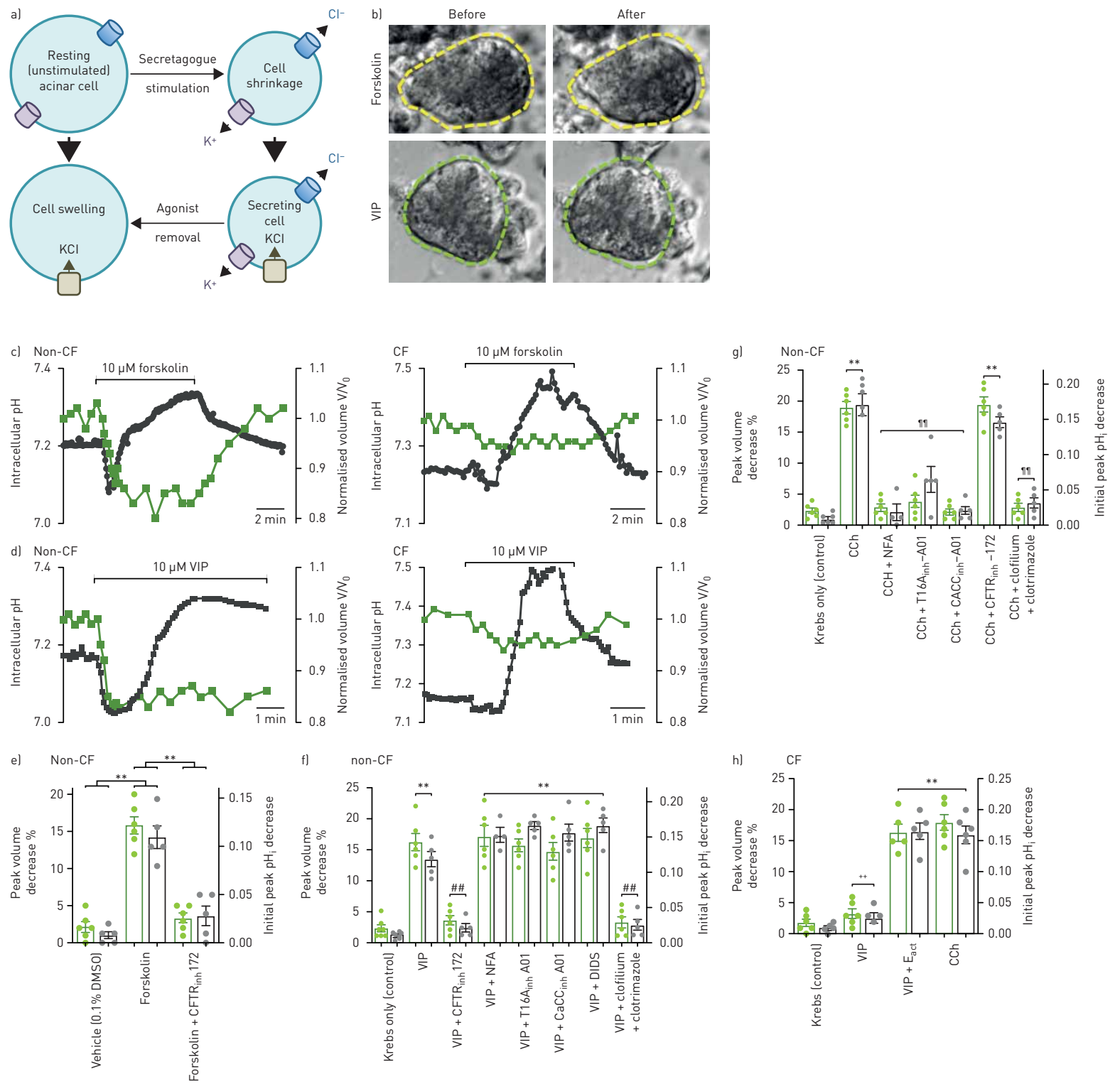

f) non-CF
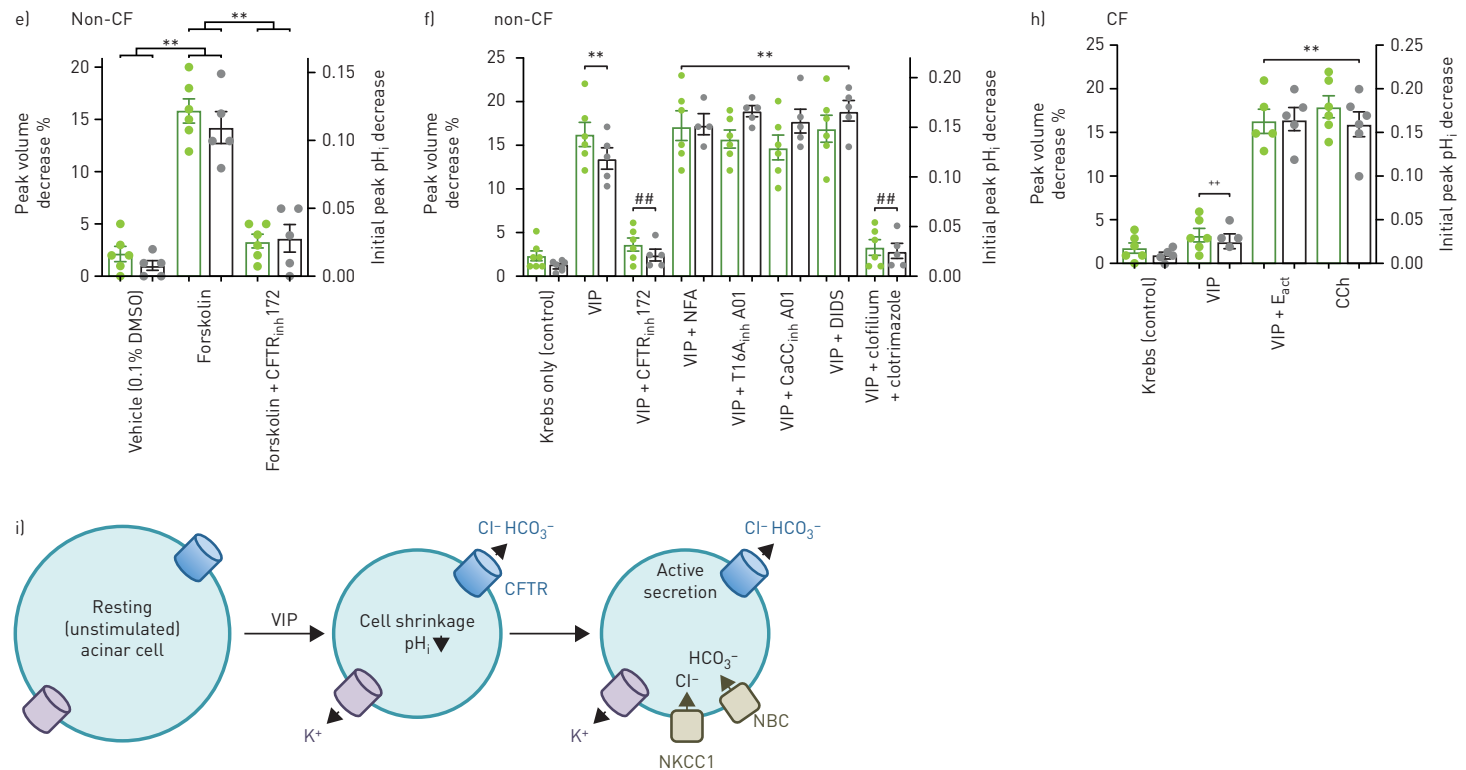

FIGURE 1 cAMP stimulation of human nasal serous cells results in cystic fibrosis transmembrane receptor (CFTR)-dependent $\mathrm{Cl}^{-}$and $\mathrm{HCO}_{3}^{-}$ secretion. a) Diagram showing use of cell volume measurements to track fluid secretion, primarily driven by $\mathrm{Cl}^{-}$, which was combined with simultaneous measurement of $\mathrm{pH}_{\mathrm{i}}$ to track $\mathrm{HCO}_{3}^{-}$secretion. b) Non-cystic fibrosis (CF) serous cells stimulated with adenylyl cyclase-activating forskolin (top) or $\mathrm{G}_{\mathrm{s}}$-coupled receptor agonist vasoactive intestinal peptide (VIP) (bottom) exhibited $\sim 15 \%$ shrinkage reflecting the activation of fluid secretion. $\mathrm{c}$ and d) In cells from non-CF patients, forskolin (c) or VIP (d) induced shrinkage ( 15\%; green) accompanied by a transient decrease in pH ( 0.1-0.15 unit; grey) followed by a sustained secondary alkalinisation. CF cells exhibited markedly reduced shrinkage and acidification; subsequent alkalinisation was intact. e-h) Bar graphs showing peak shrinkage (green) and acidification (grey) in non-CF (e-g) and CF (h) cells. Forskolin-induced shrinkage and acidification was inhibited by CFTR $_{\text {inh }} 172(10 \mu \mathrm{M})$ (e). VIP-induced shrinkage and acidification was inhibited by CFTR inh $^{172}$ and $\mathrm{K}^{+}$ channel inhibitors clofilium and clotrimazole $\left(30 \mu \mathrm{M}\right.$ each) (f). $\mathrm{Ca}^{2+}$-activated $\mathrm{Cl}^{-}$channel inhibitors NFA $(100 \mu \mathrm{M}), \mathrm{T} 16 \mathrm{~A}_{\text {inh }}-\mathrm{A} 01(10 \mu \mathrm{M}), \mathrm{CaCC}$ inh-A01 $(10 \mu \mathrm{M})$ or 4,4'-diisothiocyanostilbene-2-2"-disulfonic acid (DIDS; $1 \mathrm{mM}$ ) had no effect on VIP-induced responses (f) but blocked carbachol (CCh; $100 \mu \mathrm{M})$ responses. CF cells exhibited minimal responses to VIP but intact responses to CCh. VIP responses were restored by TMEM16A-activator $\mathrm{E}_{\text {act }}$ $(25 \mu \mathrm{M})$. All experiments done at $37^{\circ} \mathrm{C}$ with $5 \% \mathrm{CO}_{2} / 25 \mathrm{mM} \mathrm{HCO}_{3}^{-}$. Data in e-h are mean \pm SEM of $5-8$ individual experiments from $\geqslant 4$ individual patients (1-2 experiments per patient). Significances determined by one-way ANOVA, Bonferroni posttest. i) Diagram showing activation of serous cell secretion by VIP, with $\mathrm{Cl}^{-}$and $\mathrm{HCO}_{3}^{-}$efflux through CFTR lapically localised in intact glands) causing a decrease in cell volume and $\mathrm{pH}_{\mathrm{i}}$. Influx of $\mathrm{Cl}^{-}$though $\mathrm{NKCC} 1$ and influx of $\mathrm{HCO}_{3}^{-}$through NBC (both basolaterally localised in intact glands) maintains the driving force for $\mathrm{Cl}^{-}$and $\mathrm{HCO}_{3}^{-}$efflux during sustained secretion. ${ }^{* *}$ : $p<0.01$ versus control; ${ }^{\# \#}: p<0.01$ versus VIP; ${ }^{\text {ๆा }: ~} p<0.01$ versus $C C h ;{ }^{++}: p<0.01$ versus non-CF. 
magnitudes of VIP-evoked acidification and shrinkage were reduced with NPY (figure $2 \mathrm{a}$ and $\mathrm{b}$ ). We hypothesised that $\mathrm{G}_{\mathrm{i}}$-coupled NPYRs might blunt the magnitude of VIP-evoked cAMP increases, reducing CFTR activation. We measured $\mathrm{Cl}^{-}$permeability using 6-methoxy- $N$-(3-sulfopropyl)quinolinium (SPQ), a dye quenched by $\mathrm{Cl}^{-}$but not by $\mathrm{NO}_{3}^{-}$. Substitution of extracellular $\mathrm{Cl}^{-}$for $\mathrm{NO}_{3}^{-}$results in decreased intracellular $\left[\mathrm{Cl}^{-}\right]$and the resulting rate of SPQ fluorescence increase is roughly equivalent to anion permeability $[7,33,35]$. In the presence of VIP, fluorescence rapidly increased upon $\mathrm{NO}_{3}^{-}$substitution. This was reduced by $\sim 50 \%$ by NPY (figure $2 \mathrm{c}$ and $\mathrm{d}$ ). In the presence of $\mathrm{CFTR}_{\mathrm{inh}} 172$, anion permeability was almost completely reduced and NPY had no effect (figure 2d). Even after $24 \mathrm{~h}$ stimulation with NPY, isolated serous cells exhibited reduced VIP-activated $\mathrm{Cl}^{-}$permeability during acute VIP stimulation (supplementary figure S5).

CFTR is activated by PKA downstream of cAMP. We imaged real-time cAMP changes using an mNeonGreen cAMP biosensor (cADDis) [37]. VIP induced a rapid, reversible increase in cAMP blocked by VIPR antagonist VIP $(6-28)$ (figure $3 \mathrm{a}$ and $\mathrm{b}$ ). The cAMP increase was independent of $\mathrm{Ca}^{2+}$ (figure 3c). There was no difference in cAMP increases in non-CF or CF cells (supplementary figure S6), in contrast to previous hypotheses of defective cAMP signalling in CF [38]. However, NPY reduced VIP-evoked cAMP responses (figure 3d and e); the NPY effects were eliminated with NPY1R antagonist BIBO 3304 or pertussis toxin (PTX), which inactivates $\mathrm{G}_{\mathrm{i}}$ proteins (figure $3 \mathrm{~d}$ and e). Thus, NPY blunts CFTR-mediated $\mathrm{Cl}^{-}, \mathrm{HCO}_{3}^{-}$, and fluid secretion by reducing cAMP signalling.

NPY and VIP have opposing effects on $\mathrm{Cl}^{-}$and $\mathrm{HCO}_{3}^{-}$secretion in primary cultures of serous cells To facilitate polarised studies, we used culture methods that preserved a serous phenotype [34]. Serous cells cultured at the ALI expressed markers Muc7, VIPR1, VIPR2, lysozyme, NKCC1 and $\alpha_{1}$-antitrypsin, as well as both NPY1R and NPY4R (figure $4 \mathrm{a}-\mathrm{c}$ ). Lysozyme, Muc7, VIPR1 and VIPR2 were detected by immunofluorescence in serous cells (figure 4d and e) and Calu-3 cells (supplementary figure S7 and S8). ELISA and qPCR confirmed that serous cultures expressed Muc7 but not Muc5AC or Muc5B (supplementary figure S9). Serous ALIs also expressed functional CFTR. Apical substitution of $\mathrm{Cl}^{-}$for $\mathrm{NO}_{3}^{-}$led to a decrease in $\left[\mathrm{Cl}^{-}\right]_{\mathrm{i}}$ that was enhanced by VIP, blocked by $\mathrm{CFTR}_{\text {inh }} 172$, and blunted by NPY (figure 5a). Similar to the aforementioned freshly isolated cells, TMEM16A inhibitors did not affect VIP-activated $\mathrm{Cl}^{-}$permeability (figure 5a). ALIs were resistant to viral expression of cADDis, but steady-state cAMP levels were measured $5 \mathrm{~min}$ after stimulation with VIP \pm NPY. NPY reduced cAMP increases, and this was abrogated by PTX (figure $5 b$ ).

ASL was labelled with Texas red dextran to track fluid secretion. VIP increased ASL height; this was inhibited by NKCC1 inhibitor bumetanide, PKA inhibitor H89, or $\mathrm{VIP}_{(6-28)}$ (figure $5 \mathrm{c}$ and $\mathrm{d}$ ), supporting that this reflected fluid secretion. NPY inhibited VIP-induced secretion (figure $5 \mathrm{c}$ and $\mathrm{d}$ ) and isoproterenol-induced secretion (figure $5 \mathrm{~d}$ ), but not $\mathrm{Ca}^{2+}$-activated $\mathrm{CCh}$-induced secretion (figure $5 \mathrm{~d}$ ), showing effects of NPY were specific for cAMP. To test if phagocyte-produced NPY could produce these effects, we used primary human monocyte-derived macrophages primed with phorbol myristate acetate (PMA), which produce NPY (supplementary figure S10). Serous ALI transwells were transferred into plates above the macrophages with $24 \mathrm{~h}$ macrophage-conditioned media on the basolateral side. Addition of VIP increased ASL height, but this was reduced in the presence of PMA-primed macrophages, and this effect was reversed by BIBO 3304 (figure 5e).

To track $\mathrm{HCO}_{3}^{-}$secretion, ASL was labelled with seminaptharhodafluor (SNARF)-1-dextran sonicated in perfluorocarbon, allowing measurement of $\mathrm{pH}$ in physiological ASL with no addition of aqueous fluid [39]. Steady-state unstimulated ASL pH ( $\mathrm{pH}_{\mathrm{ASL}}$ ) was $7.2 \pm 0.04$, equivalent to $\sim 15 \mathrm{mM} \mathrm{HCO}-\mathrm{H}_{3}^{-}$at $5 \% \mathrm{CO}_{2}$ $\left(\left[\mathrm{HCO}_{3}^{-}\right]_{\mathrm{i}}=1.2 \mathrm{mM} \times 10^{\mathrm{pH}-6.1}\right) ; \mathrm{pH}_{\mathrm{ASL}}$ was reduced by NBC inhibitor DNDS $\left(6.9 \pm 0.06 ; 7.6 \mathrm{mM} \mathrm{HCO}_{3}^{-}\right)$but not with NPY alone (figure 5f). VIP increased $\mathrm{pH}_{\mathrm{ASL}}\left(7.6 \pm 0.04 ; 38 \mathrm{mM} \mathrm{HCO}_{3}^{-}\right)$, suggesting VIP stimulated $\mathrm{HCO}_{3}^{-}$secretion; increased $\mathrm{pH}_{\mathrm{ASL}}$ was reduced by NPY (7.3 \pm 0.05$)$ or DNDS (7.1 \pm 0.03$)$. Effects of NPY were blocked by PTX. NPY similarly inhibited forskolin and isoproterenol (figure 5f). Note that with increased ASL volume (figure 5c) and buffering capacity, actual secreted $\mathrm{HCO}_{3}^{-}$would be larger than changes in $\left[\mathrm{HCO}_{3}^{-}\right]$.

Serous ALIs were incubated with unstimulated or PMA-stimulated macrophages as previously stated and steady-state $\mathrm{pH}_{\mathrm{ASL}}$ was measured $2 \mathrm{~h}$ later; $\mathrm{pH}_{\mathrm{ASL}}$ was unchanged by unstimulated macrophages, but PMA-stimulated macrophages reduced $\mathrm{pH}_{\mathrm{ASL}}$ (figure $5 \mathrm{~g}$ ). This was inhibited by BIBO 3304 . Addition of VIP increased $\mathrm{pH}_{\mathrm{ASL}}$ (figure $5 \mathrm{~g}$ ). Effects observed were verified using a real-time $\mathrm{HCO}_{3}^{-}$secretion assay, which also confirmed secretion was dependent on apical CFTR (supplementary figure S11).

Type 2 inflammation was suggested to upregulate $\mathrm{Cl}^{-} / \mathrm{HCO}_{3}^{-}$exchanger pendrin in airway surface epithelial cells $[40,41]$. We examined if NPY or IL-13 induced altered expression of pendrin or $\mathrm{Cl}^{-}$ channels in primary serous cells, perhaps shifting serous cells away from CFTR toward a more 

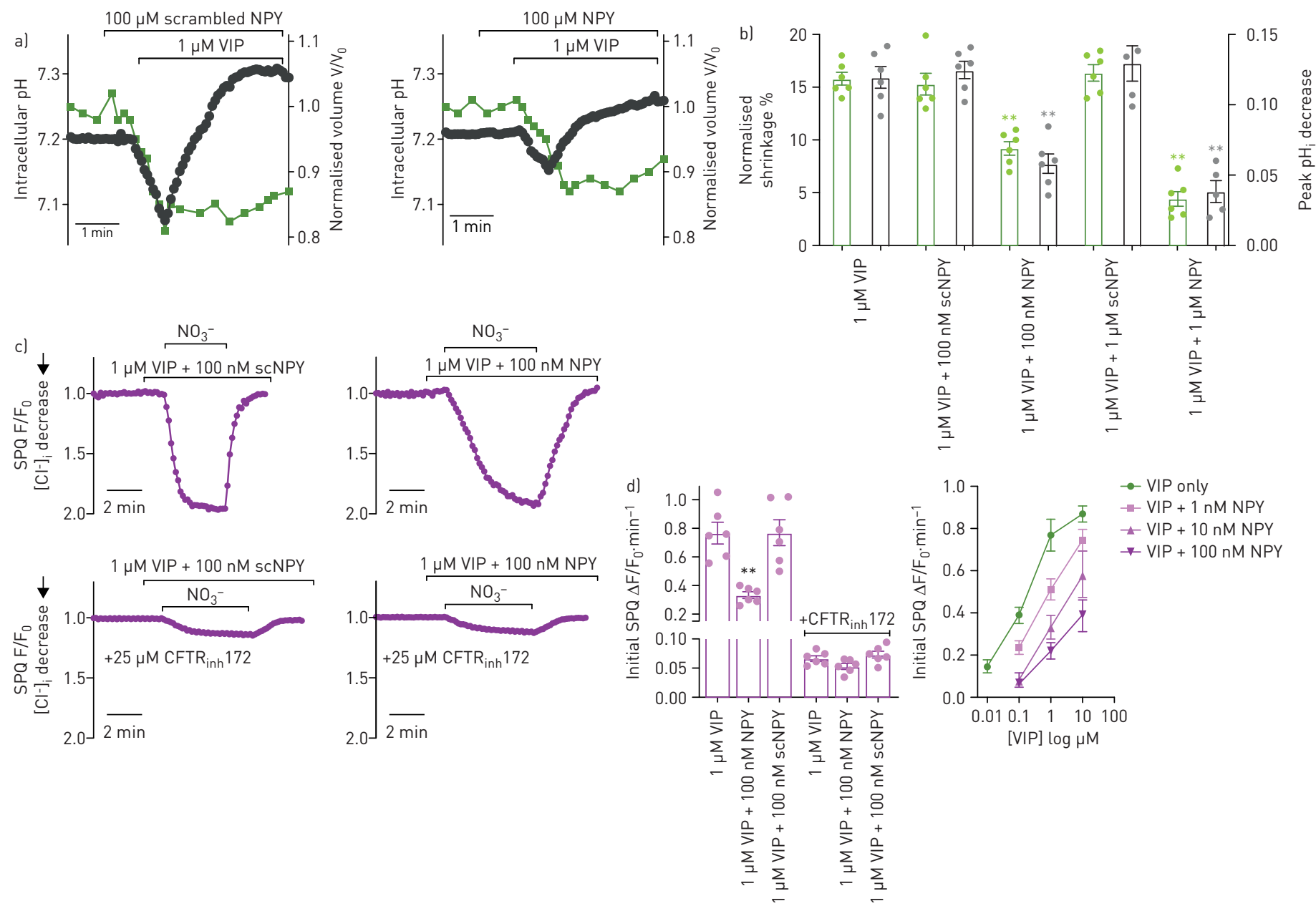

FIGURE 2 Neuropeptide Y (NPY) reduces secretory responses to vasoactive intestinal peptide (VIP) by reducing anion efflux though cystic fibrosis transmembrane receptor (CFTR) in primary nasal gland serous cells. a) Representative traces showing cell volume (green) and $\mathrm{pH}_{\mathrm{i}}$ (grey) in cells stimulated with VIP in the presence of scrambled NPY (scNPY; left) or NPY (right). b) Bar graph showing peak responses. Cells stimulated with VIP in the presence of NPY exhibited reduced shrinkage $\left(\mathrm{Cl}^{-}\right.$secretion) and initial acidification ( $\mathrm{HCO}_{3}^{-}$secretion). Significance determined by 1 -way ANOVA with Dunnett's post-test (VIP only as control group). ${ }^{* *}$ : $\mathrm{p}<0.01$ versus control. c) Representative $\mathrm{NO}_{3}^{-}$substitution experiments showing changes in 6-methoxy-N-(3-sulfopropyl)quinolinium (SPQ) fluorescence with substitution of extracellular $\mathrm{Cl}^{-}$for $\mathrm{NO}_{3}^{-}$, which causes a decrease in $\left[\mathrm{Cl}^{-}\right]_{i}$ and change in $\mathrm{SPQ}$ fluorescence. The rate of fluorescence change reflects the relative plasma membrane anion permeability. A downward deflection equals a decrease in [Cl- $]_{i}$. d) Left is bar graph of initial rate of SPQ fluorescence change after VIP stimulation, which was inhibited by NPY but not ScNPY. In the presence of CFTR $R_{\text {inh }} 172(10 \mu M)$, rates of SPQ fluorescence change were reduced $\sim 10$-fold and there was no effect of NPY. Right shows rates of SPQ fluorescence change over a range of VIP and NPY concentrations, showing dose dependency of VIP activation of anion permeability and NPY inhibition of anion permeability. Significance determined by 1 -way ANOVA with Bonferroni post-test; $a$ and $c$ show representative traces, while $b$ and $d$ show mean \pm SEM from $\geqslant 6$ experiments using cells from $\geqslant 3$ patients ( $\geqslant 2$ experiments per patient), with ${ }^{* *}: p<0.01$ versus VIP only. 

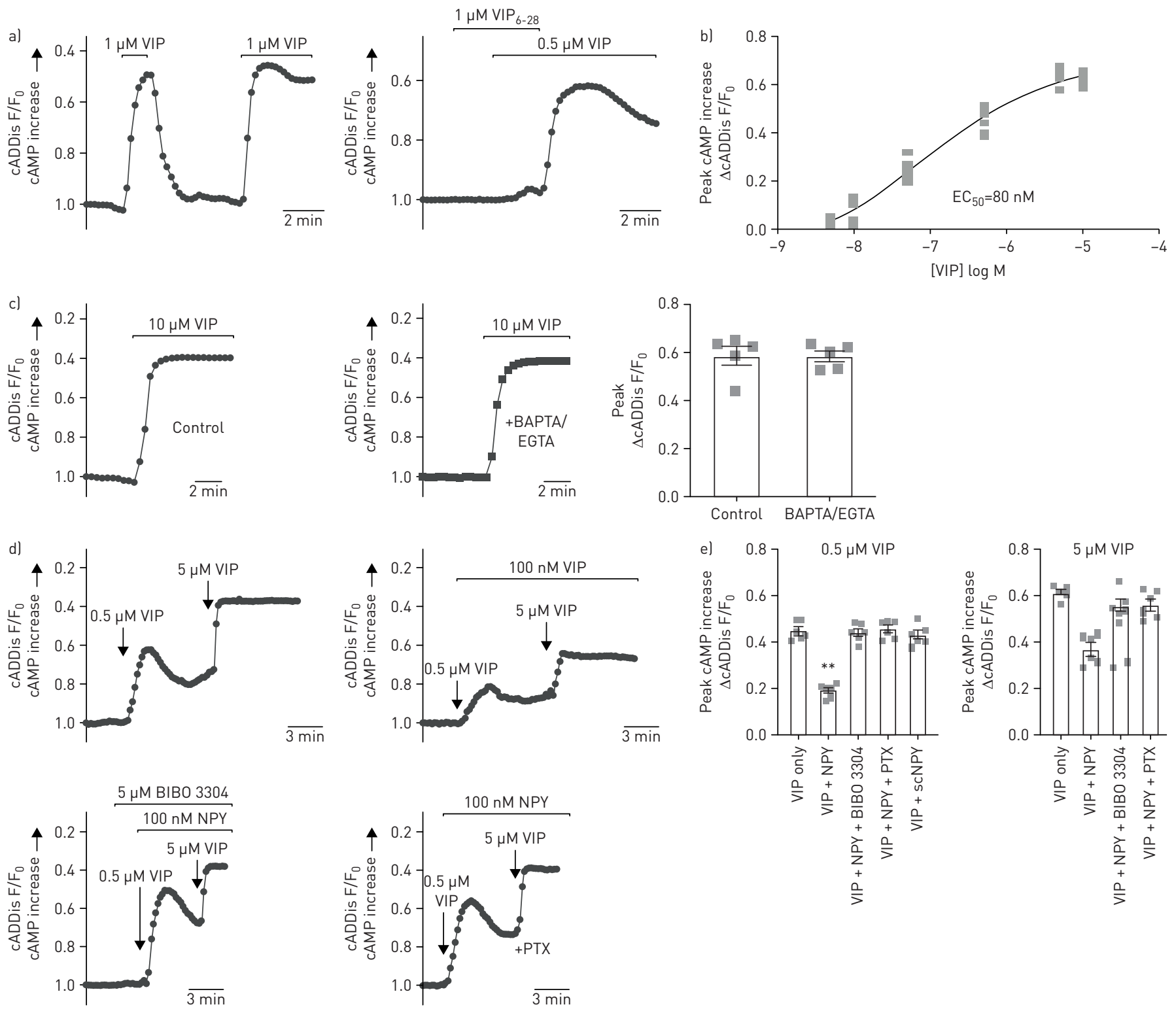

FIGURE 3 Neuropeptide Y (NPY) inhibits vasoactive intestinal peptide (VIP)-induced CAMP increases in primary nasal gland serous cells. a) Representative traces of cADDis fluorescence (upward deflection of trace=increase in CAMP) showing reversible VIP-activated cAMP increases blocked by VIP receptor antagonist VIP 6 -28. b) Dose-response showing peak cADDis fluorescence changes with VIP. Each data point is a separate experiment; graph shows data from at $\geqslant 3$ serous cells from $\geqslant 3$ patients ( 1 experiment per patient) for each [VIP]. c) Representative traces and bar graph showing intact cADDis responses with calcium chelation by $10 \mu \mathrm{M}$ BAPTA-AM loading (30 min) and stimulation in solution containing no added calcium $+1 \mathrm{mM}$ EGTA. Bar graph shows mean \pm SEM of 5 experiments using cells from 5 different patients (1 experiment per patient). No significant difference by Student's t-test. d) Peak cAMP responses to $0.5 \mu \mathrm{M}$ and $5 \mu \mathrm{M}$ VIP (top left) were inhibited by NPY (top right); NPY reduction of cAMP responses were abolished by NPY1R antagonist BIBO 3304 ( $5 \mu \mathrm{M}$; bottom left) or pertussis toxin (PTX; 6 hrs. pretreatment). e) Bar graphs showing peak responses (mean \pm SEM) from experiments as in $D$ at two different [VIP]; data points from $\geqslant 6$ experiments using cells from at least three patients ( $\geqslant 2$ experiments per patient). Significance determined by 1-way ANOVA with Dunnett's post test (VIP only as control); **: $p<0.01$ versus VIP only.

TMEM16A- and/or pendrin-dominated secretory phenotype. However, there was no change in SLC26A4 (encoding pendrin), ANO1 (encoding TMEM16A) or CFTR expression in primary serous ALIs after $24 \mathrm{~h}$ IL-13 or NPY (supplementary figure S12). Up-regulation of pendrin was observed in surface epithelial cells (supplementary figure S12), fitting a lack of a role for pendrin in serous cells [36].

VIP acutely increases antimicrobial secretions and bactericidal activity while NPY reduces it Carbonate and/or $\mathrm{HCO}_{3}^{-}$have been reported to enhance antimicrobial activity of airway secretions [42]. We observed a small effect of $\mathrm{HCO}_{3}^{-}$on antimicrobial activity of secretions produced by Calu-3 cells 

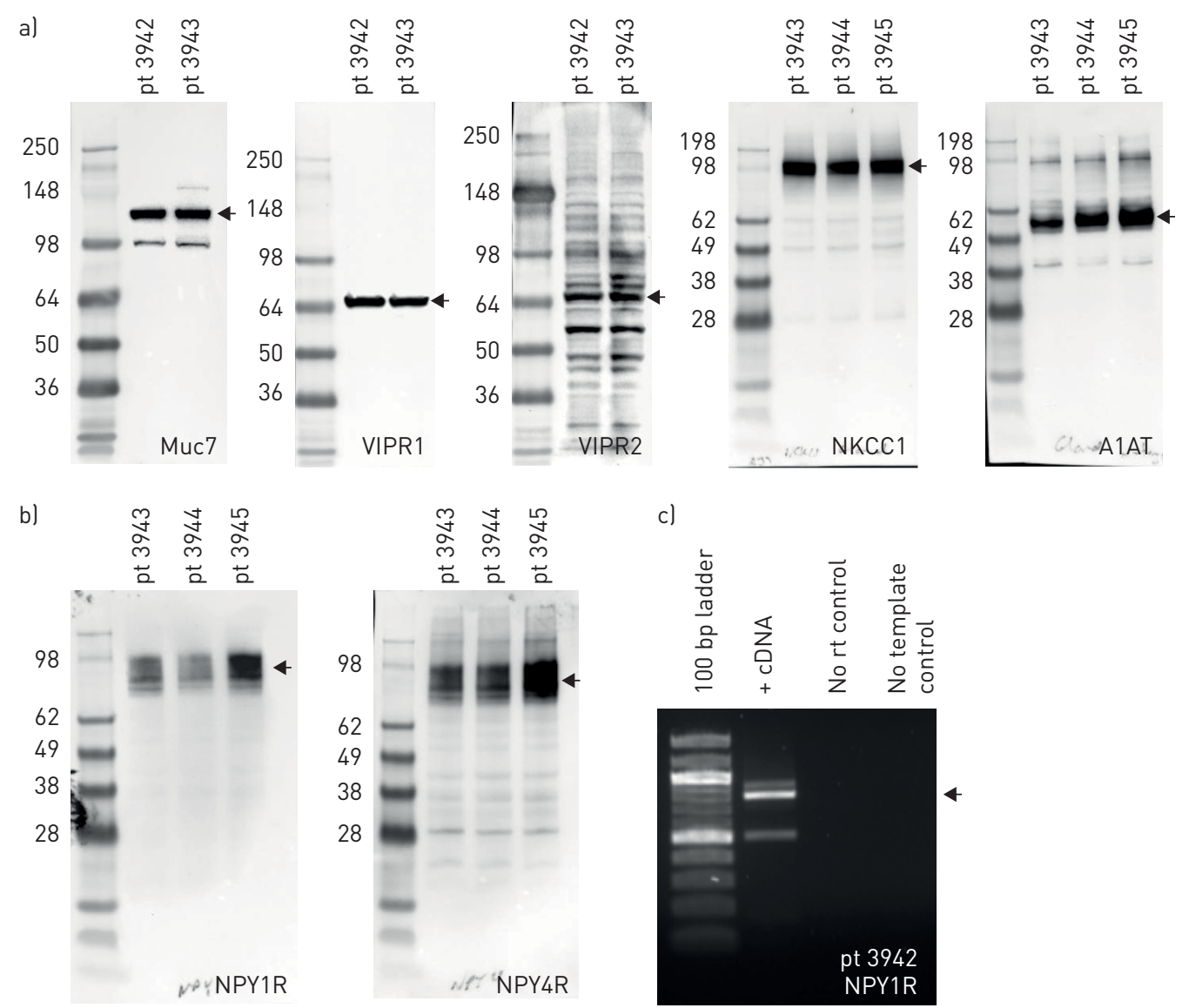

c)
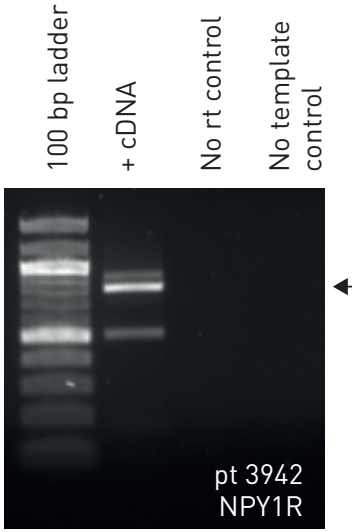

d)
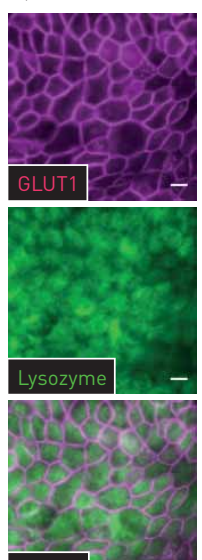

Merge
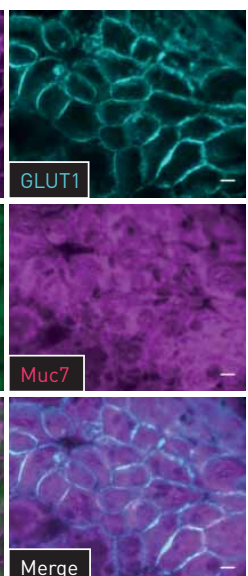
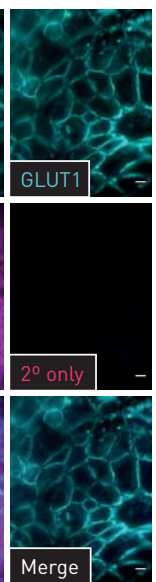

e)

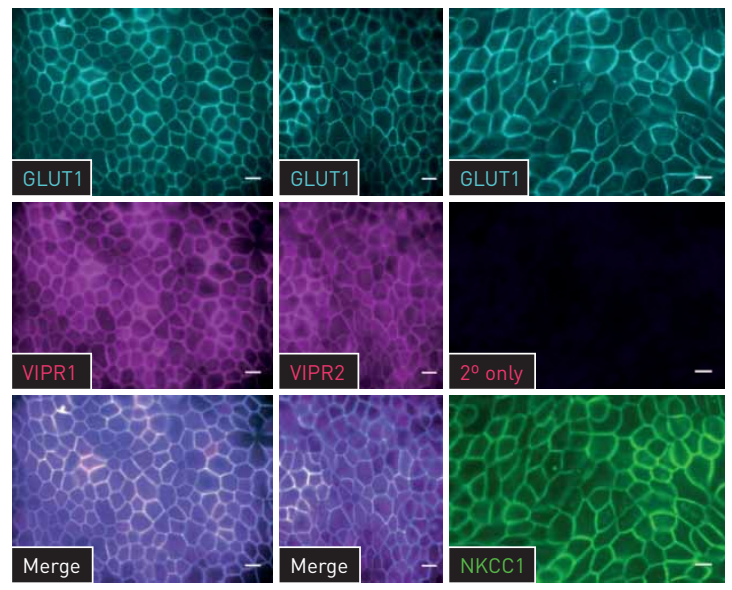

FIGURE 4 Expression of serous cell markers by primary nasal serous ALI cultures. a) Acinar cells isolated from middle turbinate were cultured and subject to Western blot for serous cell markers Muc7, vasoactive intestinal peptide (VIP) receptors VIPR1 and VIPR2, NKCC1 and $\alpha_{1}$-antitrypsin $\left(\alpha_{1} A T\right)$. Results from cultures from 2-3 patients are shown, representative of results observed from at least three independent experiments. b) Western blot for NPY1R and NPY4R (running at the molecular weight of a dimer due to unboiled samples; see supplementary methods) in cultures from three patients (representative blot from three independent experiments). c) Representative rtPCR showing expression of mRNA for NPY1R in serous ALI; results representative of three independent experiments from three patients. d) Fixed cultures were immunostained for serous markers lysozyme and Muc7, which showed punctate cytoplasmic staining similar to serous-like secretory granules. e) Immunocytochemistry for VIPR and VIPR2 revealed lateral membrane staining similar to GLUT1 and NKCC1. All images in $d$ and e are representative of cultures from $\geqslant 3$ separate patients. Scale bars are $20 \mu \mathrm{m}$. 

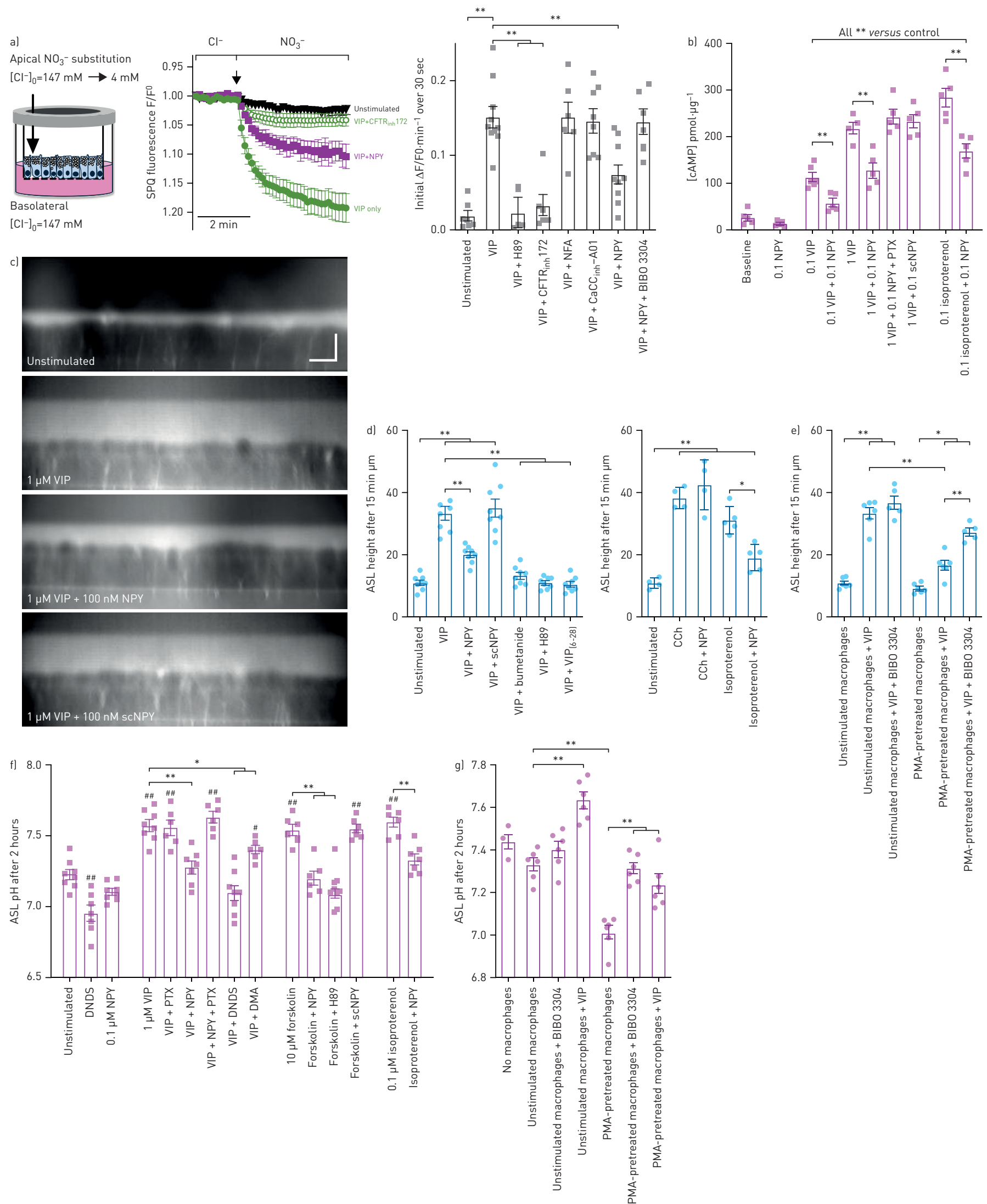

FIGURE 5 Modulation of fluid and $\mathrm{HCO}_{3}^{-}$secretion by vasoactive intestinal peptide (VIP) and neuropeptide $\mathrm{Y}$ (NPY) in serous air-liquid interface (ALI) cultures. a) Apical $\mathrm{NO}_{3}^{-}$substitution experiments (representative traces, left) and rates of SPQ change (bar graph, right) during stimulation with VIP $(1 \mu \mathrm{M})_{ \pm}$NPY $(100 \mathrm{nM})$ in the presence or absence of indicated inhibitors. b) ELISA results from steady-state cAMP measurements during 
stimulation with VIP or isoproterenol \pm NPY or scrambled NPY (scNPY). Concentrations shown are $\mu$ M. c) Representative orthogonal slices of Texas red dextran-labelled airway surface liquid (ASL) in primary serous ALIs; scale bar is $10 \mu \mathrm{m}$ in both $x$ and $z$. d) ASL height after 15 min basolateral stimulation as indicated. e) Primary human macrophages were incubated for 24 hrs with or without phorbol myristate acetate (PMA), followed by washing to remove PMA and further $24 \mathrm{~h}$ incubation in phenol red-free media alone. ASL height was measured in ALIs incubated in the presence of the macrophages and macrophage-conditioned media with basolateral compounds added as indicated. $\mathrm{f}$ ) $\mathrm{ASL} \mathrm{pH}$ ( $\mathrm{pH} \mathrm{ASL}_{\mathrm{S}} \mathrm{measured}$ using SNARF-1-dextran in cultures stimulated as indicated for $2 \mathrm{~h}$. As SNARF-1 is ratiometric, it is insensitive to changes in volume. Concentrations shown are $\mu \mathrm{M} . \mathrm{g}) \mathrm{pH}_{\mathrm{ASL}}$ in ALIs incubated in the presence of macrophages and macrophage-conditioned media as in e with basolateral compounds added as indicated. All bar graphs show mean \pm SEM of $\geqslant 6$ independent experiments using ALI cultures from $\geqslant 3$ patients $1 \geqslant 2$ cultures per patient). Significance in each bar graph determined by one-way ANOVA with Bonferroni posttest; *: $p<0.05$ and **: $p<0.01$ versus bracketed groups; and $^{\# \#}: p<0.05$ and ${ }^{\#}: p<0.01$ in $f$ versus unstimulated conditions.

(supplementary figure S13). However, we hypothesised that NPY might have more profound effects through inhibition of both $\mathrm{HCO}_{3}^{-}$secretion via CFTR and reduction of serous cell antimicrobial peptide secretion, likely mediated by a combination of constitutive and regulated vesicular release driven by both $\mathrm{Ca}^{2+}$ and cAMP, as in salivary and pancreatic exocrine acinar cells [43,44]. Reductions of cAMP by NPY may lower antimicrobial secretion independent of effects on CFTR function.

Forskolin and VIP both increased secretion of serous cell antimicrobials lysozyme, Muc7 and $\beta$-defensin 1 ( $\mathrm{h} \beta \mathrm{D} 1$ ) over $2 \mathrm{~h}$ as measured by ELISA; this was reduced by NPY (figure 6a). There was no effect of inhibition of CFTR or TMEM16A on secretion of these antimicrobials (supplementary figure S14a). Neither lysozyme nor h $\beta D 1$ secretion was reduced in cultures derived from CF patients (supplementary figure S14b). NPY had no effect on CCh-activated secretion of lysozyme or h $\beta D 1$ over $2 \mathrm{~h}$ (supplementary figure S14c), supporting a specific effect of NPY on cAMP. Fitting with increased antimicrobial peptide secretion, VIP acutely increased the antibacterial effects of serous ASL washings against clinical isolates of Pseudomonas aeruginosa and methicillin-resistant Staphylococcus aureus (MRSA; figure 6b and c). NPY blunted the effects of VIP (figure $6 \mathrm{~b}$ and $\mathrm{c}$ ). A fluorescent live-dead staining of $P$. aeruginosa confirmed reduced bactericidal efficacy of NPY+VIP-stimulated ASL (supplementary figure S15).

Neither VIP nor NPY alone had longer-term (24-48 hrs) effects on expression of h $\beta D 1$ by qPCR (supplementary figure S16a) despite increased secretion over $48 \mathrm{~h}$ (supplementary figure s16b). lipopolysaccharide (LPS) treatment up-regulated $\mathrm{h} \beta \mathrm{D} 2$ expression and secretion (supplementary figure S16a-c), but this was not significantly affected by NPY or VIP. Lysozyme expression was significantly increased by VIP at $24 \mathrm{~h}$ (supplementary figure S16d), with lysozyme and Muc7 secretion also increased at $24 \mathrm{~h}$ (supplementary figure S16e). VIP-treated cultures exhibited more bactericidal ASL even at $48 \mathrm{~h}$, reduced by NPY even in the presence of LPS (supplementary figure S16f). Thus, more chronic VIP and NPY stimulation can have longer term effects on serous cell antimicrobials.

\section{NPY is pro-inflammatory}

We hypothesised that airway gland cytokine secretion may be modulated by VIP and/or NPY. We first focussed on epithelial cell-derived cytokines involved in asthma and allergy, where alterations of VIP and/ or NPY have been reported. In serous ALIs, IL-6, tumour necrosis factor (TNF) $\alpha$, IL-1 $\beta$, and granulocytemacrophage colony-stimulating factor (GM-CSF) release were increased after $48 \mathrm{~h}$ treatment with toll-like receptor 4 (TLR4) activator LPS, TLR3 activator poly(I:C), TLR2 activator lipotechoic acid (LTA), TNF $\alpha$ or type 2 cytokines (IL-4+IL-13; supplementary figure S17a-d). While NPY or VIP had no effect alone on IL-6, TNF $\alpha$, or GM-CSF release, NPY increased IL-1 $\beta$ release $\sim 2$-fold at baseline. NPY also increased IL-1 $\beta$ mRNA at $4 \mathrm{~h}$ (supplementary figure S17e)

NPY also potentiated release of these cytokines in combination with LPS, LTA, IL-4+IL-13, and TNF- $\alpha$ (supplementary figure S17a-d). NPY also enhanced LPS-induced IL-6 and IL-8 mRNA as well as IL-13or TNF- $\alpha$-induced GM-CSF mRNA at $4 \mathrm{~h}$ (supplementary figure S17f-g). NPY effects were blocked by PTX, implicating $\mathrm{G}_{\mathrm{i}}$ signalling (supplementary figure S17a-d). In contrast, VIP reduced cytokine secretion 25-50\%; these reductions were eliminated by NPY (supplementary figure S17a-d). Co-stimulation with IL-4+IL-13 increased cytokines in response to either poly(I:C) or LPS, and this was enhanced further by NPY (supplementary figure S18a), suggesting that NPY is pro-inflammatory even within the context of Th2 inflammation observed in airway diseases like asthma.

NPY also enhanced cytokine release in response to heat-killed clinical isolates of $P$. aeruginosa and MRSA (figure $7 \mathrm{a}-\mathrm{c}$ ), which likely activate TLRs as previously mentioned. To validate results from cultured ALIs, we incubated freshly dissociated serous cells with TNF $\alpha$ or poly(I:C) $\pm N P Y$; NPY enhanced cytokine secretion (supplementary figure S18b), confirming NPY is pro-inflammatory and may contribute to increased inflammation in airway diseases like asthma. 

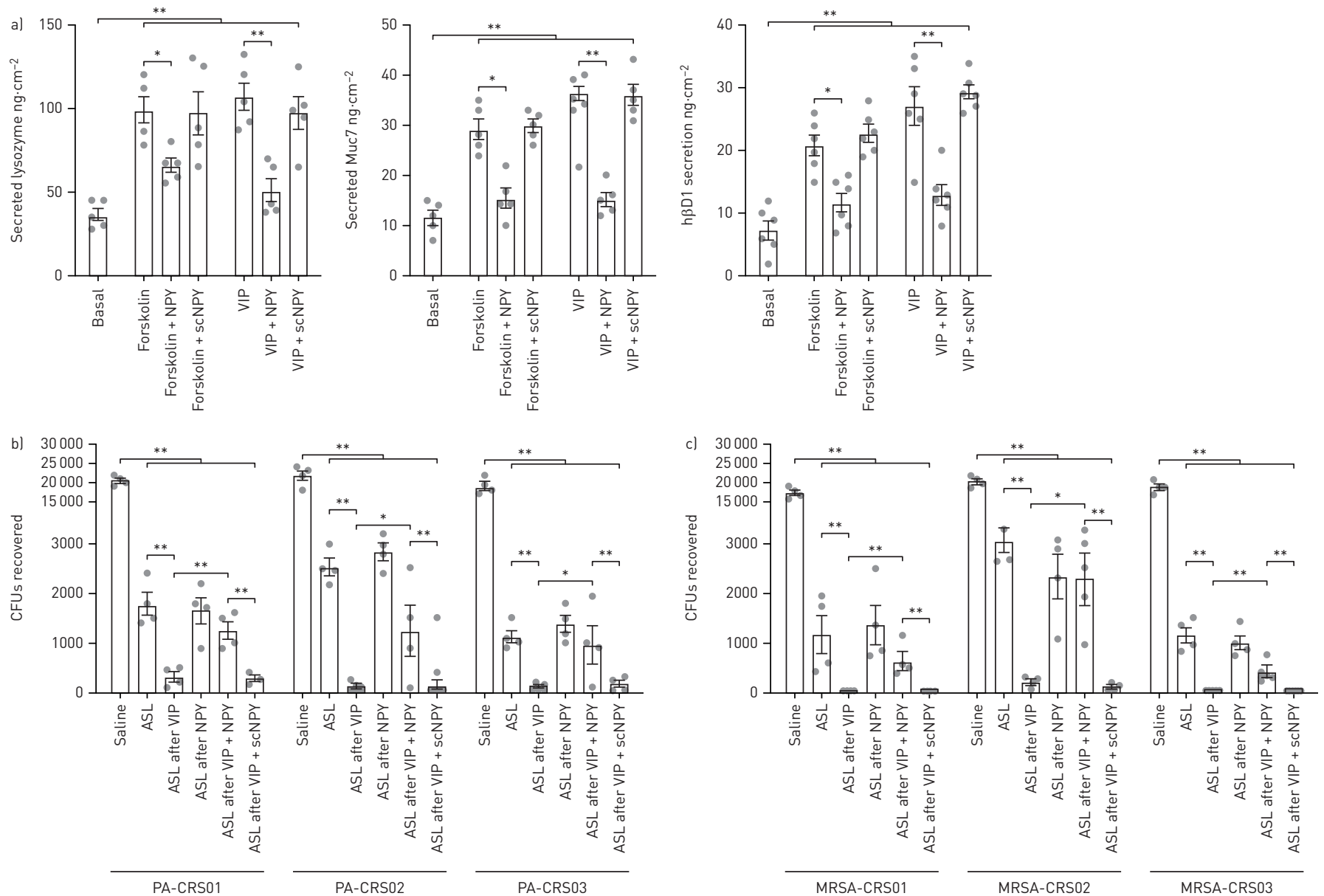

FIGURE 6 Antimicrobial peptide secretion and antibacterial efficacy of serous cells secretions are acutely enhanced by vasoactive intestinal peptide (VIP) but reduced by neuropeptide Y (NPY). a) air-liquid interface cultures (ALIs)were stimulated basolaterally (2 hrs) with forskolin $(10 \mu \mathrm{M})$ or VIP $(1 \mu \mathrm{M}) \pm$ NPY $(100 \mathrm{nM})$ or scrambled NPY (scNPY; $100 \mathrm{nM})$ as indicated. ASL was collected by washing the apical surface with $25 \%$ saline and assayed for lysozyme, Muc7, and hBD1 by ELISA. Results are mean \pm SEM from $\geqslant 3$ ALIs from $\geqslant 3$ individual patients (one ALI per patient). b-c) ASL from similar experiments was mixed with Pseudomonas aeruginosa (b) or MRSA (c) isolated from chronic rhinosinusitis (CRS) patients followed by incubation $\left(2 \mathrm{hrs} ; 37^{\circ} \mathrm{C} ; 5 \% \mathrm{CO}_{2}\right)$, dilution, and plating for colony forming unit counting. Bar graphs show mean \pm SEM of $\geqslant 5$ experiments using ALIs from $\geqslant 3$ different patients. ${ }^{* *}: p<0.01$ and ${ }^{*}: p<0.05$ between bracketed groups. Significance determined by one-way ANOVA with Bonferroni post-test.

Anti-inflammatory effects of VIP require functional CFTR conductance; TMEM16A can substitute In airway cells, $\mathrm{Cl}^{-}$conductance may be anti-inflammatory $[45,46]$, with increased $\left[\mathrm{Cl}^{-}\right]_{\mathrm{i}}$ promoting inflammation [47]. This may have implications for CF; in serous cells stimulated with $\mathrm{VIP},\left[\mathrm{Cl}^{-}\right]_{\mathrm{i}}$ may be higher in CF cells due to lack of CFTR-mediated efflux. We tested if CFTR contributes to anti-inflammatory effects of VIP using NPY to increase release of IL-1 $\beta$, a cytokine upregulated in the lungs of some children with CF $[48,49]$. NPY-induced IL- $1 \beta$ was not altered by $\mathrm{CFTR}_{\text {inh }} 172$ or TMEM16A activator $\mathrm{E}_{\text {act }}$ (figure $7 \mathrm{~d}$ ). However, VIP reduced IL- $1 \beta$ by $>50 \%$ (figure $7 \mathrm{~d}$ ). $\mathrm{CFTR}_{\text {inh }} 172$ reversed the effect of VIP, while $\mathrm{E}_{\text {act }}$ restored effects of VIP, and the effect of $\mathrm{E}_{\text {act }}$ was further reversed with $\mathrm{CaCC}_{\text {inh }}-\mathrm{A} 01$ (figure $7 \mathrm{~d}$ ). We saw similar results when serous cells were stimulated with heat-killed $P$. aeruginosa. VIP reduced release of GM-CSF and IL-6, another cytokine involved in early CF inflammation [48]; this was blocked by $\mathrm{CFTR}_{\text {inh }} 172$ but subsequently restored by $\mathrm{E}_{\text {act }}$ (figure $7 \mathrm{e}$ ).

Thus, CFTR is required for anti-inflammatory effects of VIP, but TMEM16A can substitute. However, activation of $\mathrm{Cl}^{-}$conductance by $\mathrm{E}_{\text {act }}$ was not sufficient for anti-inflammatory effects in the absence of VIP (figure 7e), likely because a reduction in $\left[\mathrm{Cl}^{-}\right]_{\mathrm{i}}$ requires counter-ion $\left(\mathrm{K}^{+}\right)$flux activated downstream of secretagogues [33] but not activated by $\mathrm{E}_{\mathrm{act}}$ alone. Supporting this, $\mathrm{K}^{+}$channel activator 1-ethyl-2-benzimidazolinone (1-EBIO) [7] in combination with $\mathrm{E}_{\text {act }}$ was anti-inflammatory in serous cells (figure 7e). VIP also reduced $P$. aeruginosa-induced release of IL-8 (figure 7f), another cytokine upregulated in CF $[48,49]$. 

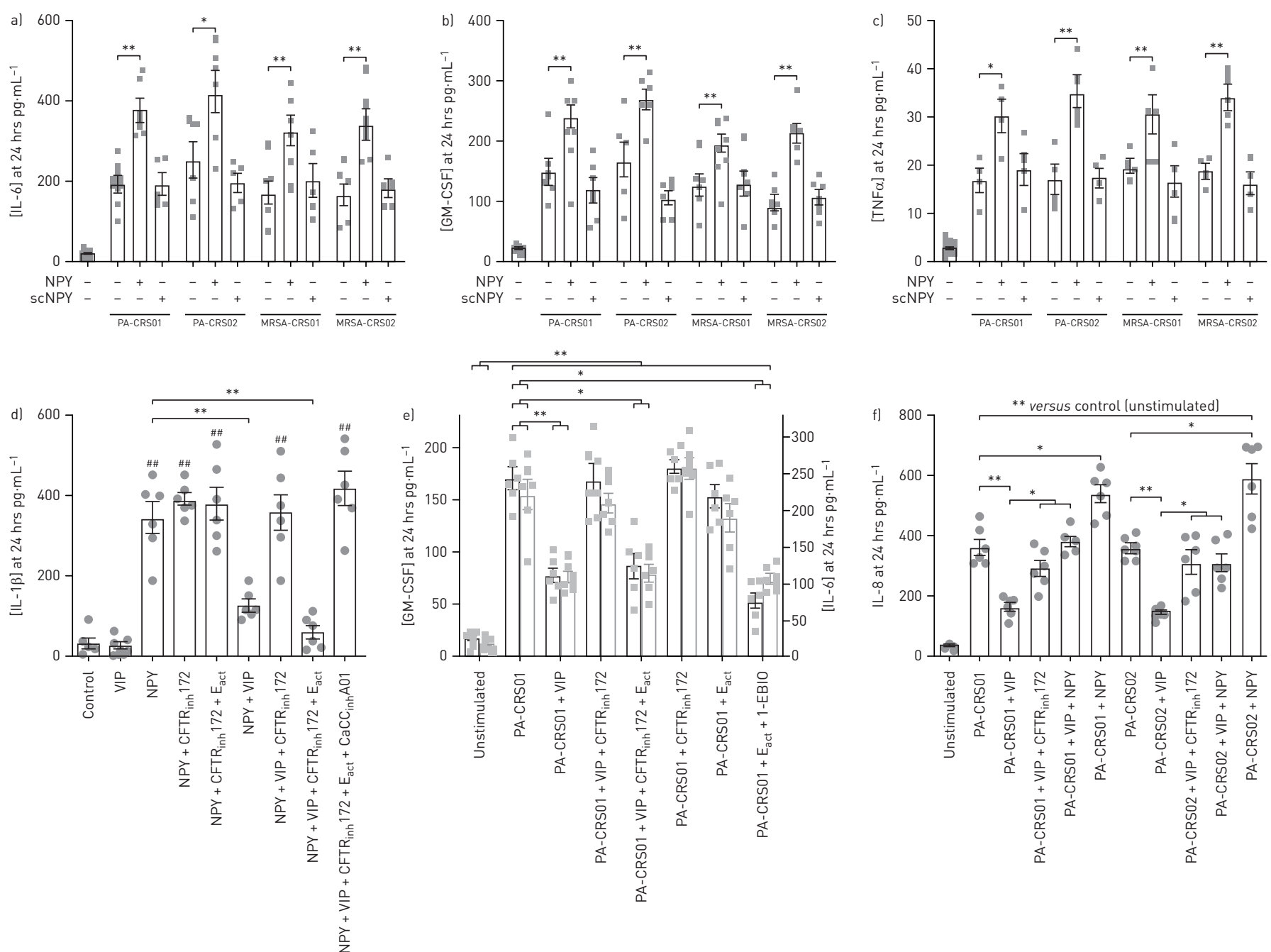

FIGURE 7 Serous cell cytokine secretion in response to bacteria is increased by neuropeptide $Y$ (NPY) and decreased by vasoactive intestinal peptide (VIP) in a cystic fibrosis transmembrane conductance regulator (CFTR)-dependent manner. a-c) Primary serous cell air-liquid interface cultures (ALIs) were treated apically with heat-killed bacteria, followed by $24 \mathrm{~h}$ incubation \pm basolateral NPY (100 nM) or scrambled NPY (scNPY; $100 \mathrm{nM}$ ). Basolateral media was collected for quantification of interleukin (IL)-6 (a), granulocyte-macrophage colony-stimulating factor (GM-CSF) (b), and tumour necrosis factor (TNF)- $\alpha$ (c). Bar graphs shown mean \pm SEM of $\geqslant 5$ experiments using cells grown from $\geqslant 3$ different patients. d) Primary serous ALIs were treated basolaterally with VIP $(100 \mu \mathrm{M})$ and/or NPY $(100 \mathrm{nM})$ and treated apically with CFTR inhibitor CFTR inh $_{172}$ $(15 \mu \mathrm{M})$, TMEM16A activator $\mathrm{E}_{\text {act }}(15 \mu \mathrm{M})$, and/or TMEM16A inhibitor $\mathrm{CaCC}_{\text {inh }}$-A01 $(15 \mu \mathrm{M})$. Basolateral media was collected after $24 \mathrm{hrs}$. and assayed for IL-1 $\beta$. e-f) Primary serous ALIs were treated apically with heat-killed Pseudomonas aeruginosa, followed by 24 hrs incubation \pm basolateral NPY and/or VIP as well as \pm apical CFTR inh $_{172}$ and/or $E_{\text {act }}$ and/or 1-EBIO $(150 \mu \mathrm{M})$. Basolateral media was collected and assayed for GM-CSF (e), IL-6 (e), or IL-8 (f) by ELISA. Significance by one-way ANOVA with Bonferroni post-test comparing the three bars for each separate strain in a-c and comparing bracketed bars in $d-e .{ }^{* *}: p<0.01 ;{ }^{*}: p<0.05$.

\section{Discussion}

This study suggests serous cells secrete $\mathrm{HCO}_{3}^{-}$in addition to $\mathrm{Cl}^{-}$during VIPergic stimulation directly through CFTR (figure 8a). NPY impairs both VIPergic fluid and antimicrobial peptide secretion by reducing cAMP signalling (figure 8b). The novel inverse relationship between NPY and VIP in the regulation of secretion suggests that the balance of these neuropeptides affects mucus rheology by promoting or inhibiting $\mathrm{Cl}^{-}$and $\mathrm{HCO}_{3}^{-}$secretion from serous cells, which control the hydration of mucins secreted by more proximal gland mucous cells.

This study reveals several insights relevant to CF pathogenesis (figure 8c). We found no evidence of $\mathrm{Cl}^{-} /$ $\mathrm{HCO}_{3}^{-}$exchange (e.g. pendrin) activity in serous cells, suggesting loss of CFTR function directly contributes to impaired $\mathrm{HCO}_{3}^{-}$secretion. Targeting CFTR via correctors and/or potentiators would restore serous cell $\mathrm{HCO}_{3}^{-}$and $\mathrm{Cl}^{-}$secretion independent of other proteins. Moreover, cAMP signalling was intact in CF cells, suggesting that appropriate pharmacological correction of mutant CFTR could restore secretion in response to the appropriate endogenous physiological stimuli (e.g. VIP). In CF patients that cannot benefit from CFTR correction (e.g. premature stop codon mutations), activation of TMEM16A 


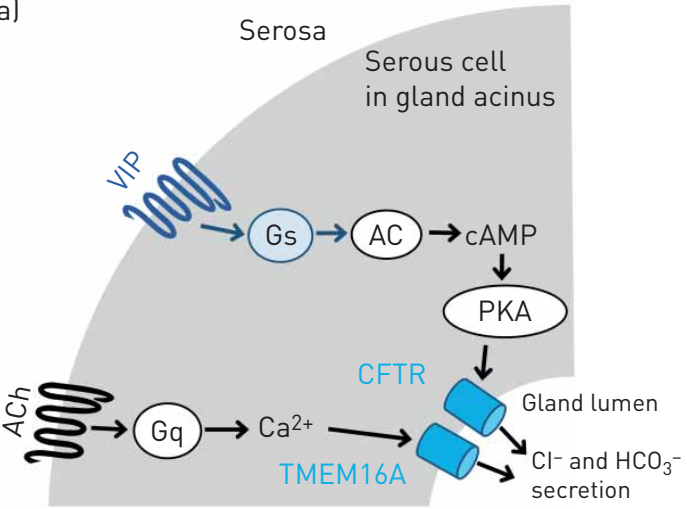

b)

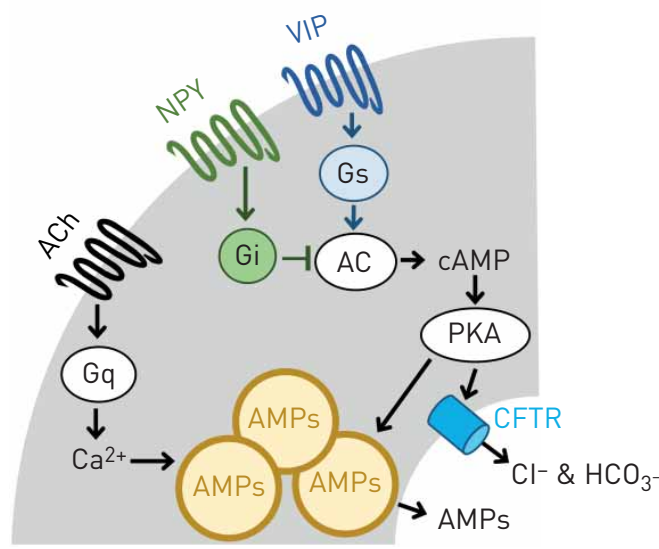

c)

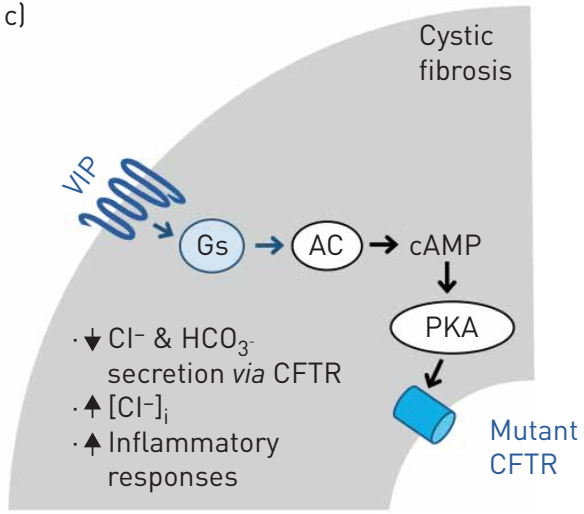

d)

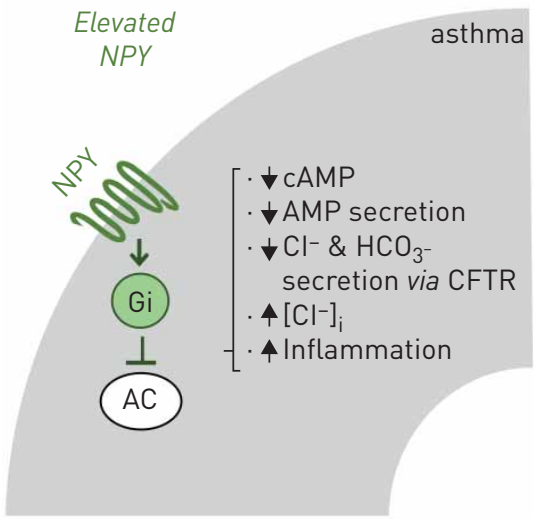

FIGURE 8 Model of vasoactive intestinal peptide (VIP)-ergic and neuropeptide $Y$ (NPY)-ergic regulation of serous cell function and implications for airway diseases. al Activation of VIP receptors on serous cells allows $G \alpha_{S}\left(G s\right.$ ) activation of adenylyl cyclase (AC), elevation of $c A M P$, and $\mathrm{Cl}^{-}$and $\mathrm{HCO}_{3}^{-}$efflux through protein kinase A (PKA)-activated cystic fibrosis transmembrane conductance regulator (CFTR). In contrast, activation of muscarinic receptors by acetylcholine (ACh) stimulates $\mathrm{G} \alpha_{q}(\mathrm{Gq})$-dependent calcium $\left(\mathrm{Ca}^{2+}\right.$ ) elevation and $\mathrm{Cl}^{-} / \mathrm{HCO}_{3}^{-}$secretion through TMEM16A (based on data here and $[3,7]$ ). While regulated by two independent pathways, our data suggest CFTR and TMEM16A are functionally equivalent anion efflux pathways. A result of $\mathrm{Cl}^{-}$efflux (and parallel $\mathrm{K}^{+}$efflux, not shown [7]) is a reduction intracellular $\mathrm{Cl}^{-}$concentration ([Cl- $\left.]_{i}\right)$ (b) NPY receptors, in contrast, activate $\mathrm{G} \alpha_{i}$ (Gi) proteins to inhibit AC and reduce VIP-activated cAMP responses. This blunts both the CFTR-mediated anion secretion as well as VIP-activated antimicrobial peptide (AMP) secretion, likely vesicular secretion. NPY has no effects on cholinergic anion or AMP secretion because it is driven by $\mathrm{Ca}^{2+}$ rather than CAMP. c) We hypothesise that, in cystic fibrosis, VIP cannot elicit anion and fluid secretion via CFTR. Also, since $\left[\mathrm{Cl}^{-}\right]_{\text {i }}$ remains elevated, inflammatory responses may be increased. d) In asthma, elevated NPY may increase Gi activity to blunt cAMP responses downstream of VIP, reducing CFTR activity and fluid secretion as well as vesicular AMP secretion. NPY also has pro-inflammatory effects.

could also restore $\mathrm{Cl}^{-} / \mathrm{HCO}_{3}^{-}$efflux. As CFTR may regulate other channels and transporters like the epithelial $\mathrm{Na}^{+}$channel or pendrin in surface epithelial cells [36, 40,41], TMEM16A activation may not fully replace CFTR. However, this study and previous work [6] suggest TMEM16A can support levels of $\mathrm{Cl}^{-}$and $\mathrm{HCO}_{3}^{-}$efflux from serous cells equivalent to CFTR.

These results also reveal potential pathophysiological mechanisms in obstructive airway diseases like asthma (figure 8d). Elevated VIP in allergic rhinitis may promote watery serous secretions through elevated fluid and $\mathrm{HCO}_{3}^{-}$secretion to thin mucus. However, under conditions of increased NPY (e.g. in asthma), the ability of VIP to stimulate fluid and $\mathrm{HCO}_{3}^{-}$secretion through CFTR and antimicrobial peptide secretion is impaired due to a blunting of cAMP signalling. NPY also decreases airway ciliary beat frequency [50], which may further impair mucociliary clearance and innate defence. Increased inflammation via elevated NPY may exacerbate these effects. In summary, our data suggest that in some asthma, COPD or CRS patients, NPYR1 antagonists may be useful to thin secreted mucus, enhance antimicrobial secretion, and/or reduce inflammation.

While elevated NPY has not been reported in CF lungs, one study did suggest elevated NPY in olfactory epithelium of CFTR knockout mice [51]. It may be possible that NPY plays a role in a subset of CF 
patients; skewing toward at Th17 or Th2 profile may be a risk factor for P. aeruginosa infection in CF lungs [52]. NPY might be elevated in these patients. NPY would not be expected to substantially affect ion transport in CF serous cells as the entire pathway is already absent due to loss of CFTR function; however, NPY could still reduce antimicrobial secretion or promote inflammation. A role for NPY in CF lungs and potential therapeutic value of NPYR inhibition requires further investigation. Regardless of NPY's relevance to CF pathophysiology, increased mucus viscosity in CF and asthma may share, at least in part, common mechanisms of reduced CFTR function. In CF, this is via direct CFTR mutation. In asthma, reduced CFTR-mediated secretion due to elevated NPY and blunted cAMP signalling may contribute to poorly hydrated gland mucus independent of direct CFTR defects.

The important contribution of exocrine cells to inflammation is established in parotid and pancreatic acini within the context of Sjögren's syndrome and pancreatitis, respectively [53]. However, this is less studied in the airway. Bronchial gland volume may be $\geqslant 50$-fold the volume of goblet cells [3]. Gland acini are likely significant contributors of cytokines [54], particularly when gland hypertrophy and hyperplasia occur during COPD and asthma [3]. Our data support previous observations $[45,46]$ that the $\mathrm{Cl}^{-}$channel activity of CFTR is anti-inflammatory during VIP stimulation, and may contribute to hyperinflammatory phenotypes reported in CF [45,46]. Exocrine acinar cells accumulate $\mathrm{Cl}^{-}$above electrochemical equilibrium $\left(\geqslant 65 \mathrm{mM}\left[\mathrm{Cl}^{-}\right]_{\mathrm{i}}\right)$ [7] to support their dedicated fluid-secreting role. VIP stimulation lowers $\left[\mathrm{Cl}^{-}\right]_{\mathrm{i}}(\sim 30 \mathrm{mM})$ in serous cells via $\mathrm{KCl}$ efflux through CFTR and $\mathrm{K}^{+}$channels. Changes in serous cell intracellular $\left[\mathrm{Cl}^{-}\right]$during stimulation are likely greater than the changes in surface epithelial cells, where resting intracellular $\left[\mathrm{Cl}^{-}\right]_{\mathrm{i}}$ is lower $(\leqslant 40 \mathrm{mM})$. Thus, the pro-inflammatory effects of elevated $\left[\mathrm{Cl}^{-}\right]_{\mathrm{i}}$ may be more pronounced in serous cells, increasing inflammation in the absence of CFTR function. Similar to $\mathrm{Cl}^{-}$and $\mathrm{HCO}_{3}^{-}$secretion, our data suggest that activation of TMEM16A could compensate for loss of CFTR, suggesting possible anti-inflammatory benefit to targeting TMEM16A in glands of patients who cannot utilise CFTR potentiator/corrector therapies.

Interestingly, NPY increased cytokine production during co-stimulation with TLR agonists, but it had less effect on $\beta$-defensin 2 , which is also regulated by TLR-stimulated nuclear factor $(\mathrm{NF}) \kappa \mathrm{B}$. This may suggest that NPY potentiates TLR-induced cytokine secretion via a non-NFKB mechanism, supported by the observation that NPY alone did not induce IL-6 or IL-8. Future work is needed to more fully dissect out the molecular details of NPYR signalling pathway in airway cells, including activated transcription factors.

Acknowledgements: We thank N. Cohen (Philadelphia VA Medical Center) for bacteria isolates, J. Riley (University of Pennsylvania Human Immunology Core) for access to human monocytes, M. Victoria (University of Pennsylvania) for assistance with macrophage differentiation and molecular biology, B. Chen (University of Pennsylvania) for assistance growing initial serous cultures, and J.K. Foskett (University of Pennsylvania) for initial training in many techniques used.

Author contributions: D.B. McMahon, R.M. Carey, M.A. Kohanski and R.J. Lee performed experiments and analysed data. R.M. Carey, M.A. Kohanski, C.C.L. Tong, P. Papagiannopoulos, N.D. Adappa and J.N. Palmer aided with tissue procurement, primary cell acquisition and culture, maintenance of clinical records, and intellectually contributed. D.B. McMahon, R.M. Carey and R.J. Lee drafted the manuscript with critical input and approval from all authors.

Conflict of interest: D.B. McMahon has nothing to disclose. R.M. Carey has nothing to disclose. M.A. Kohanski has nothing to disclose. C.C.L. Tong has nothing to disclose. P. Papagiannopoulos has nothing to disclose. N.D. Adappa has nothing to disclose. J.N. Palmer has nothing to disclose. R.J. Lee reports grants from NIH/National Institute of Allergy and Infections Disease, NIH/National Institute of Deafness and Other Communication Disorders and Cystic Fibrosis Foundation, during the conduct of the study.

Support statement: Work was funded by grants from the Cystic Fibrosis Foundation (LEER16G0, LEE19G0) and National Institutes of Health (R21AI137484, R01DC016309). Primary human monocytes were obtained from the University of Pennsylvania Human Immunology Core, supported by National Institutes of Health P30CA016520 and P30AI045008. Funding information for this article has been deposited with the Crossref Funder Registry.

\section{References}

1 Rogers DF. Physiology of airway mucus secretion and pathophysiology of hypersecretion. Respir Care 2007; 52: 1134-1146.

2 Kato K, Song BH, Howe CL, et al. A comprehensive systematic review of the association between airway mucins and chronic rhinosinusitis. Am J Rhinol Allergy 2019; 33: 433-448.

3 Widdicombe JH, Wine JJ. Airway gland structure and function. Physiol Rev 2015; 95: 1241-1319.

4 Chen FH, Samson KT, Miura K, et al. Airway remodeling: a comparison between fatal and nonfatal asthma. J Asthma 2004; 41: 631-638.

5 Kunzelmann K, Schreiber R, Hadorn HB. Bicarbonate in cystic fibrosis. J Cyst Fibros 2017; 16: 653-662.

6 Lee RJ, Harlow JM, Limberis MP, et al. HCO3(-) secretion by murine nasal submucosal gland serous acinar cells during Ca2+-stimulated fluid secretion. J Gen Physiol 2008; 132: 161-183.

7 Lee RJ, Foskett JK. Ca2+ signaling and fluid secretion by secretory cells of the airway epithelium. Cell Calcium 2014; 55: 325-336

8 Baraniuk JN, Kaliner MA. Neuropeptides and nasal secretion. J Allergy Clin Immunol 1990; 86: 4 Pt. 2, 620-627. 
9 Baraniuk JN, Lundgren JD, Okayama M, et al. Vasoactive intestinal peptide in human nasal mucosa. J Clin Invest 1990; 86: 825-831.

10 Chanez P, Springall D, Vignola AM, et al. Bronchial mucosal immunoreactivity of sensory neuropeptides in severe airway diseases. Am J Respir Crit Care Med 1998; 158: 985-990.

11 Tanaka Y, Yoshida Y, Hirano M. Precise localization of VIP-, NPY-, and TH-immunoreactivities of cat laryngeal glands. Brain Res Bull 1995; 36: 219-224.

12 Heppt W, Dinh QT, Cryer A, et al. Phenotypic alteration of neuropeptide-containing nerve fibres in seasonal intermittent allergic rhinitis. Clin Exp Allergy 2004; 34: 1105-1110.

13 Groneberg DA, Heppt W, Cryer A, et al. Toxic rhinitis-induced changes of human nasal mucosa innervation. Toxicol Pathol 2003; 31: 326-331.

14 Bowden JJ, Gibbins IL. Vasoactive intestinal peptide and neuropeptide Y coexist in non-noradrenergic sympathetic neurons to guinea pig trachea. J Auton Nerv Syst 1992; 38: 1-19.

15 Luts A, Uddman R, Alm P, et al. Peptide-containing nerve fibers in human airways: distribution and coexistence pattern. Int Arch Allergy Immunol 1993; 101: 52-60.

16 Uddman R, Sundler F, Emson P. Occurrence and distribution of neuropeptide-Y-immunoreactive nerves in the respiratory tract and middle ear. Cell Tissue Res 1984; 237: 321-327.

17 Fang SY, Shen CL, Ohyama M. Presence of neuropeptides in human nasal polyps. Acta Otolaryngol 1994; 114: 324-328.

18 Fujiwara S, Hoshizaki M, Ichida Y, et al. Pulmonary phagocyte-derived NPY controls the pathology of severe influenza virus infection. Nat Microbiol 2019; 4: 258-268.

19 Li S, Koziol-White C, Jude J, et al. Epithelium-generated neuropeptide Y induces smooth muscle contraction to promote airway hyperresponsiveness. J Clin Invest 2016; 126: 1978-1982.

20 Augustyniak D, Nowak J, Lundy FT. Direct and indirect antimicrobial activities of neuropeptides and their therapeutic potential. Curr Protein Pept Sci 2012; 13: 723-738.

21 Makinde TO, Steininger R, Agrawal DK. NPY and NPY receptors in airway structural and inflammatory cells in allergic asthma. Exp Mol Pathol 2013; 94: 45-50.

22 Lu Y, Ho R, Lim TK, et al. Neuropeptide Y may mediate psychological stress and enhance TH2 inflammatory response in asthma. J Allergy Clin Immunol 2015; 135: 1061-1063.

23 Macia L, Rao PT, Wheway J, et al. Y1 signalling has a critical role in allergic airway inflammation. Immunol Cell Biol 2011; 89: 882-888.

24 Prod'homme T, Weber MS, Steinman L, et al. A neuropeptide in immune-mediated inflammation, Y? Trends Immunol 2006; 27: 164-167.

25 Buttari B, Profumo E, Domenici G, et al. Neuropeptide Y induces potent migration of human immature dendritic cells and promotes a Th2 polarization. FASEB J 2014; 28: 3038-3049.

26 Mosimann BL, White MV, Hohman RJ, et al. Substance P, calcitonin gene-related peptide, and vasoactive intestinal peptide increase in nasal secretions after allergen challenge in atopic patients. J Allergy Clin Immunol 1993; 92: 1 Pt. 1, 95-104.

27 Lee RJ, Chen B, Doghramji L, et al. Vasoactive intestinal peptide regulates sinonasal mucociliary clearance and synergizes with histamine in stimulating sinonasal fluid secretion. FASEB J 2013; 27: 5094-5103.

28 Atanasova KR, Reznikov LR. Neuropeptides in asthma, chronic obstructive pulmonary disease and cystic fibrosis. Respir Res 2018; 19: 149.

29 Merten MD, Figarella C. Neuropeptide Y and norepinephrine cooperatively inhibit human tracheal gland cell secretion. Am J Physiol 1994; 266: L513-L518.

30 Webber SE. The effects of peptide histidine isoleucine and neuropeptide $\mathrm{Y}$ on mucus volume output from the ferret trachea. Br J Pharmacol 1988; 95: 49-54.

31 Huang SC, Tsai MF. Receptors for peptide YY and neuropeptide Y on guinea pig pancreatic acini. Peptides 1994; 15: $405-410$

32 Chandrasekharan B, Nezami BG, Srinivasan S. Emerging neuropeptide targets in inflammation: NPY and VIP. Am J Physiol Gastrointest Liver Physiol 2013; 304: G949-G957.

33 Lee RJ, Foskett JK. cAMP-activated Ca2+ signaling is required for CFTR-mediated serous cell fluid secretion in porcine and human airways. J Clin Invest 2010; 120: 3137-3148.

34 Finkbeiner WE, Zlock LT, Mehdi I, et al. Cultures of human tracheal gland cells of mucous or serous phenotype. In Vitro Cell Dev Biol Anim 2010; 46: 450-456.

35 McMahon DB, Workman AD, Kohanski MA, et al. Protease-activated receptor 2 activates airway apical membrane chloride permeability and increases ciliary beating. FASEB J 2018; 32: 155-167.

36 Huang J, Kim D, Shan J, et al. Most bicarbonate secretion by Calu-3 cells is mediated by CFTR and independent of pendrin. Physiol Rep 2018; 6: e13641.

37 Tewson PH, Martinka S, Shaner NC, et al. New DAG and cAMP sensors optimized for live-cell assays in automated laboratories. J Biomol Screen 2016; 21: 298-305.

38 Kunzelmann K, Mehta A. CFTR: a hub for kinases and crosstalk of cAMP and Ca2+. FEBS J 2013; 280: 4417-4429.

39 Worthington EN, Tarran R. Methods for ASL measurements and mucus transport rates in cell cultures. Methods Mol Biol 2011; 742: 77-92.

40 Nakagami Y, Favoreto S, Jr., Zhen G, et al. The epithelial anion transporter pendrin is induced by allergy and rhinovirus infection, regulates airway surface liquid, and increases airway reactivity and inflammation in an asthma model. J Immunol 2008; 181: 2203-2210.

41 Vanoni S, Scantamburlo G, Dossena S, et al. Interleukin-mediated pendrin transcriptional regulation in airway and esophageal epithelia. Int J Mol Sci 2019; 20: E731.

42 Dorschner RA, Lopez-Garcia B, Peschel A, et al. The mammalian ionic environment dictates microbial susceptibility to antimicrobial defense peptides. FASEB J 2006; 20: 35-42.

43 Kreda SM, Seminario-Vidal L, van Heusden CA, et al. Receptor-promoted exocytosis of airway epithelial mucin granules containing a spectrum of adenine nucleotides. J Physiol 2010; 588: 2255-2267.

44 Suzuki A, Iwata J. Molecular regulatory mechanism of exocytosis in the salivary glands. Int J Mol Sci 2018; 19: E3208. 
45 Veit G, Bossard F, Goepp J, et al. Proinflammatory cytokine secretion is suppressed by TMEM16A or CFTR channel activity in human cystic fibrosis bronchial epithelia. Mol Biol Cell 2012; 23: 4188-4202.

46 Schnur A, Hegyi P, Rousseau S, et al. Epithelial anion transport as modulator of chemokine signaling. Mediators Inflamm 2016; 2016: 7596531.

47 Zhang YL, Chen PX, Guan WJ, et al. Increased intracellular $\mathrm{Cl}(-)$ concentration promotes ongoing inflammation in airway epithelium. Mucosal Immunol 2018; 11: 1149-1157.

48 Armstrong DS, Hook SM, Jamsen KM, et al. Lower airway inflammation in infants with cystic fibrosis detected by newborn screening. Pediatr Pulmonol 2005; 40: 500-510.

49 Dhooghe B, Noel S, Huaux F, et al. Lung inflammation in cystic fibrosis: pathogenesis and novel therapies. Clin Biochem 2014; 47: 539-546.

50 Lee RJ, Workman AD, Carey RM, et al. Fungal aflatoxins reduce respiratory mucosal ciliary function. Sci Rep 2016; 6: 33221 .

51 Pfister S, Weber T, Hartig W, et al. Novel role of cystic fibrosis transmembrane conductance regulator in maintaining adult mouse olfactory neuronal homeostasis. J Comp Neurol 2015; 523: 406-430.

52 Tiringer K, Treis A, Fucik P, et al. A Th17- and Th2-skewed cytokine profile in cystic fibrosis lungs represents a potential risk factor for Pseudomonas aeruginosa infection. Am J Respir Crit Care Med 2013; 187: 621-629.

53 Dios ID. Inflammatory role of the acinar cells during acute pancreatitis. World J Gastrointest Pharmacol Ther 2010; 1: 15-20

54 Furukawa E, Ohrui T, Yamaya M, et al. Human airway submucosal glands augment eosinophil chemotaxis during rhinovirus infection. Clin Exp Allergy 2004; 34: 704-711. 